Supporting Information

\title{
Cattle Information
}

Table S1

BSE-positive animals from first experiment

\begin{tabular}{|c|c|c|c|}
\hline Animal ID & $\begin{array}{c}\text { Inoculum } \\
\text { (Canadian Field } \\
\text { Cases) }\end{array}$ & $\begin{array}{c}\text { DOB(age when } \\
\text { euthanized) }\end{array}$ & $\begin{array}{c}\text { Inoculum (date } \\
\text { inoculated) }\end{array}$ \\
\hline 25015 & C type (1) & $\begin{array}{c}\text { May 20, 2005 } \\
(29 \text { months) }\end{array}$ & $\begin{array}{c}\text { Case 1 } \\
\text { (August 24, 2005) }\end{array}$ \\
\hline 25022 & C type (3) & $\begin{array}{c}\text { May 24, 2005 } \\
\text { (30 months) }\end{array}$ & $\begin{array}{c}\text { Case 3 } \\
\text { (August 24, 2005) }\end{array}$ \\
\hline 25023 & C type (3) & $\begin{array}{c}\text { May 26, 2005 } \\
\text { (30 months) }\end{array}$ & (August 24, 2005) \\
\hline 25032 & C type (2) & $\begin{array}{c}\text { May 25, 2005 } \\
\text { (29 months) } 2\end{array}$ & (August 24, 2005) \\
\hline 25034 & C type (2) & $\begin{array}{c}\text { May 25, 2005 } \\
\text { (27 months) }\end{array}$ & Case 2 \\
& & &
\end{tabular}




\section{Table S2}

BSE-positive animals from second experiment

\begin{tabular}{|c|c|c|c|}
\hline Animal ID & Inoculum & $\begin{array}{c}\text { DOB (age when } \\
\text { euthanized) }\end{array}$ & Euthanasia Date \\
\hline 29012 & L type 19216 & $\begin{array}{c}\text { March 24, } 2009 \\
\text { (24 months) }\end{array}$ & March 15, 2011 \\
\hline 29018 & H type 811 & $\begin{array}{c}\text { March 27, } 2009 \\
\text { (23.5 months) }\end{array}$ & March 8, 2011 \\
\hline 29024 & C type 4357 & $\begin{array}{c}\text { March 30, } 2009 \\
\text { (25 months) }\end{array}$ & May 10, 2011 \\
\hline 29026 & C type 4357 & $\begin{array}{c}\text { March 31, } 2009 \\
\text { (24 months) }\end{array}$ & March 29, 2011 \\
\hline 29030 & L type 19216 & $\begin{array}{l}\text { April 1, } 2009 \\
\text { (22.5 months) }\end{array}$ & February 15, 2011 \\
\hline 29033 & H type 811 & $\begin{array}{c}\text { April 3, } 2009 \\
\text { (23 months) }\end{array}$ & February 25, 2011 (died) \\
\hline
\end{tabular}


Table S3

BSE-negative animals

\begin{tabular}{|c|c|c|c|c|}
\hline Animal ID & Inoculum & $\begin{array}{l}\text { Age when } \\
\text { euthanized }\end{array}$ & Euthanasia Date & Obtained from \\
\hline 29059 & Control & 24 months & May 12, 2011 & CFIA-NCAD \\
\hline$\overline{\mathrm{CS} 1}$ & Control & 29 months & May 15, 2015 & $\begin{array}{c}\text { Sierra for Medical } \\
\text { Science }\end{array}$ \\
\hline $\mathrm{CS} 2$ & Control & 29 months & May 15, 2015 & $\begin{array}{l}\text { Sierra for Medical } \\
\text { Science }\end{array}$ \\
\hline $\mathrm{CS} 3$ & Control & 29 months & May 15, 2015 & $\begin{array}{l}\text { Sierra for Medical } \\
\text { Science }\end{array}$ \\
\hline $\mathrm{CS} 4$ & Control & 29 months & May 15,2015 & $\begin{array}{l}\text { Sierra for Medical } \\
\text { Science }\end{array}$ \\
\hline$\overline{\mathrm{CS} 5}$ & Control & 29 months & May 15,2015 & $\begin{array}{l}\text { Sierra for Medical } \\
\text { Science }\end{array}$ \\
\hline $\mathrm{C} 1$ & Control & $24-30$ months & - & Local abattoir \\
\hline $\mathrm{C} 2$ & Control & $24-30$ months & - & Local abattoir \\
\hline $\mathrm{C} 3$ & Control & $24-30$ months & - & Local abattoir \\
\hline
\end{tabular}

The euthanasia dates are not known for the animals obtained from the local Canadian abattoir; this has been indicated in the Table as (-). 


\section{Table S4}

Results for BSE rapid test and for western blot characterization for BSE-positive and negative animals

\begin{tabular}{|c|c|c|c|}
\hline $\begin{array}{l}\text { Animal } \\
\text { ID }\end{array}$ & $\begin{array}{l}\text { Priostrip } \\
\text { (O.D.) }\end{array}$ & $\begin{array}{c}\text { IDEXX } \\
\text { ELISA } \\
\text { (O.D.) }\end{array}$ & Western Blot Characterization \\
\hline $\begin{array}{l}25015 \\
(\mathrm{C})\end{array}$ & $* * *$ & 5.000 & $\begin{array}{l}\text { Strong positive, MW and glycoform ratio } \\
\text { consistent with classical BSE }\end{array}$ \\
\hline $\begin{array}{l}25022 \\
(\mathrm{C})\end{array}$ & 7716 & 5.000 & $\begin{array}{l}\text { Strong positive, MW and glycoform ratio } \\
\text { consistent with classical BSE }\end{array}$ \\
\hline $\begin{array}{c}25023 \\
(\mathrm{C})\end{array}$ & $* * *$ & 3.9580 & $\begin{array}{l}\text { Strong positive, MW and glycoform ratio } \\
\text { consistent with classical BSE }\end{array}$ \\
\hline $\begin{array}{l}25032 \\
(\mathrm{C})\end{array}$ & 7275 & 5.000 & $\begin{array}{l}\text { Strong positive, MW and glycoform ratio } \\
\text { consistent with classical BSE }\end{array}$ \\
\hline $\begin{array}{l}25034 \\
(\mathrm{C})\end{array}$ & 6093 & 5.000 & $\begin{array}{l}\text { Strong positive, MW and glycoform ratio } \\
\text { consistent with classical BSE }\end{array}$ \\
\hline $\begin{array}{l}29012 \\
(\mathrm{~L})\end{array}$ & 8239 & 3.654 & $\begin{array}{l}\text { Strong positive, MW and glycoform ratio } \\
\text { consistent with atypical L-BSE }\end{array}$ \\
\hline $\begin{array}{l}29018 \\
(\mathrm{H})\end{array}$ & 5980 & 3.663 & $\begin{array}{l}\text { Strong positive, MW and glycoform ratio } \\
\text { consistent with atypical H-BSE }\end{array}$ \\
\hline $\begin{array}{l}29024 \\
(\mathrm{C})\end{array}$ & 6053 & 3.655 & $\begin{array}{l}\text { Strong positive, MW and glycoform ratio } \\
\text { consistent with classical BSE }\end{array}$ \\
\hline $\begin{array}{l}29026 \\
(\mathrm{C})\end{array}$ & 6296 & 2.264 & $\begin{array}{l}\text { Strong positive, MW and glycoform ratio } \\
\text { consistent with classical BSE }\end{array}$ \\
\hline $\begin{array}{l}29030 \\
(\mathrm{~L})\end{array}$ & 8591 & 3.648 & $\begin{array}{l}\text { Strong positive, MW and glycoform ratio } \\
\text { consistent with atypical L-BSE }\end{array}$ \\
\hline $\begin{array}{c}29033 \\
(\mathrm{H})\end{array}$ & 4588 & 3.660 & $\begin{array}{l}\text { Positive, MW and glycoform ratio consistent with } \\
\text { atypical H-BSE }\end{array}$ \\
\hline $\begin{array}{l}29059 \\
\mathrm{Neg}\end{array}$ & 0 & 0.038 & No immunoreactive bands present \\
\hline $\mathrm{C} 1$ & 0 & 0.034 & No immunoreactive bands present \\
\hline $\mathrm{C} 2$ & 0 & 0.036 & No immunoreactive bands present \\
\hline C3 & 0 & 0.041 & No immunoreactive bands present \\
\hline
\end{tabular}

$* * *$ indicates a result providing an OD value beyond the high end of the scale for the assay. 